\title{
Clinical and Demographic Profiles of Patients Diagnosed as Cough Variant Asthma attended at Tertiary Referral Hospital
}

\author{
SK Shahinur Hossain¹, Md. Safiul Islam², Md. Mustafizur Rahman³, Shubhashish De, \\ Khurshid Mahmud ${ }^{5}$ \\ ${ }^{1}$ Assistant Professor, Department of Respiratory Medicine at National Institute of Diseases of the Chest and Hospital, \\ Dhaka, Bangladesh; ${ }^{2}$ Medical Officer, Department of Respiratory Medicine at National Institute of Diseases of \\ the Chest and Hospital, Dhaka, Bangladesh; ${ }^{3}$ OSD, Directorate General of Health Services, Ministry of \\ Health \& Family Welfare, Dhaka, Bangladesh; ${ }^{4}$ Assistant Register, Department of Medicine, \\ Shaheed Tajuddin Ahmed Medical College, Gajipur, Bangladesh; ${ }^{5}$ Associate Professor, \\ Department of Physical Medicine \& Neuro-rehabilitation, National Institute of \\ Neurosciences \& Hospital, Dhaka, Bangladesh
}

[Received: January 2015; Revised: March 2015; Accepted: June 2015; Published: January 2016]

\begin{abstract}
Background: Cough variant asthma is presented with different clinical and demographic characteristics. Objectives: The purpose of the present study was to see the clinico-demographic profiles of cough variant asthma patients. Methodology: This descriptive type of cross-sectional study was carried out in the Department of Respiratory Medicine at National Institute of Diseases of the Chest and Hospital (NIDCH), Dhaka, Bangladesh from September 2014 to August 2015 for a period of one year. Patients presented with cough variant asthma attending in NIDCH were selected as study population. Methacholine challenge test was performed to diagnosis of Cough Variant Asthma. Result: A total number of 50 patients were recruited for this study. The mean age \pm SD was found $19.1 \pm 7.6$ years. Male was predominant than female with a ratio of 1.4.:1. Among the study population positive family history of asthma was found in $39.0 \%$ cases and associated allergic rhinitis was reported in $58.0 \%$ cases. Eczema was associated with $16.0 \%$ patients; however, only 4\% patients had associate conjunctivitis. Conclusion: In conclusion young male is more commonly affected by cough variant asthma of which majority have family history of asthma. [Journal of National Institute of Neurosciences Bangladesh, 2016;2(1):30-33]
\end{abstract}

Keywords: Cough variant asthma; clinical profile; demographic characteristics; asthma

Correspondence: Dr. SK Shahinur Hossain, Assistant Professor, Department of Respiratory Medicine, National Institute of Diseases of the Chest and Hospital, Dhaka, Bangladesh; Email: dr.parvez47@gmail.com; Cell no.: +8801711355872

Conflict of interest: There is no conflict of interest to any of the authors of this article.

Funding agency: This research work was performed by own cost. There was funding agency had given the support.

Contribution to authors: SKSH, MSI, MMR \& SD were contributed from protocol preparation up to report writing. SKSH \& KM were prepared the manuscript and was revised the manuscript.

How to cite this article: Hossain SKS, IslamMS, Rahman MM, Dey S, Mahmud K. Clinical and Demographic Profiles of Patients Diagnosed as Cough Variant Asthma attended at Tertiary Referral Hospital.J NatlInstNeurosci Bangladesh 2016;2(1): 30-33

Copyright: (C2016 Hossain et al. Published by Journal of National Institute of Neurosciences Bangladesh. This article is published under the Creative Commons CC BY-NC License (https://creativecommons.org/licenses/by-nc/4.0/). This license permits use, distribution and reproduction in any medium, provided the original work is properly cited, and is not used for commercial purposes.

\section{Introduction}

Asthma is a chronic inflammatory disorder of the airways $^{1}$. It is a heterogeneous disease, with different underlying disease processes. It is associated with airway hyper-responsiveness that leads to recurrent episodes of wheezing, breathlessness, chest tightness and coughing, particularly at night and in the early morning ${ }^{2}$. These episodes are usually associated with widespread but variable airflow obstruction within the lung that is often reversible either spontaneously or with treatment ${ }^{3}$. According to the first national asthma prevalence study (NAPS) in Bangladesh about 7 million people $(5.2 \%)$ are suffering from current asthma and more than $90 \%$ do not take modern treatment ${ }^{4}$. Therefore, poorly controlled asthma remains a major problem in Bangladesh.

Cough variant asthma (CVA) is a phenotype of asthma presenting solely with coughing, characterized by airway hyper-responsiveness, eosinophilic inflammation and a cough response to bronchodilators ${ }^{5}$. 
It is a type of asthma in which the main symptom is a dry, non-productive cough ${ }^{6}$. People with cough-variant asthma or CVA often have no other "classic" asthma symptoms, such as wheezing or shortness of breath. The prevalence of CVA was $3.8 \%$ among the patients with coughing as their chief complaint and $41.8 \%$ among those with chronic cough persisting for 8 or more weeks; in addition, this disorder accounted for $61 \%$ of the patients with chronic cough that did not respond to non-specific antitussive therapy ${ }^{7}$. Therefore, the present study was undertaken to see the clinico-demographic profiles of cough variant asthma patients.

\section{Methodology}

This descriptive type of cross-sectional study was carried out in the Department of Respiratory Medicine at National Institute of Diseases of the Chest and Hospital (NIDCH), Dhaka, Bangladesh from September 2014 to August 2015 for a period of one year. Purposive sampling technique was used to select the patients. Patients with the age of more than or equal to 30 years who were suffering from chronic cough for more than 8 weeks with positive methacholine challenge test were included as study population.Smokers, patients having COPD, patients having other causes of chronic cough like post nasal drip, gastro-esophageal reflux disease, ILD, heart failure, use of ACE inhibitor drugs were excluded from this study.

In the first phase a standard questionnaire was designed with a view to collect data. Informed written consent was taken from each patient. Initial evaluation of the patient by history and clinical examination was performed and recorded in the preformed data sheet. Subjects were explained the procedure. Baseline spirometry was performed before methacholine used. Prepared 10 doubling concentrations of methacholinewere followed $0.03,0.06,0.125,0.25$, $0.50,1,2,4,8,16 \mathrm{mg} / \mathrm{dL} 2$.Methacholine challenge test was performed. Concentration of methacholine started from minimum concentration $0.03 \mathrm{mg} / \mathrm{dL}$ and gradual increased the dose up to the level at which $20.0 \%$ fall in FEV1was observed from base line or the highest concentration $(16 \mathrm{mg} / \mathrm{dL})$ of the drug had been delivered. A total of 10 doses are given if the entire procedure is finished without a positive response. Another spirometry was performed and result was recorded. Patients were resuscitated by nebulised bronchodilator.

The procedure was performed in the respiratory laboratory of NIDCH. Statistical analyses were carried out by using the Statistical Package for Social Sciences version 16.0 for Windows (SPSS Inc., Chicago, Illinois, USA). Continuous variables were expressed as mean, standard deviation, and categorical variables as frequencies and percentages.

\section{Results}

A total 50 patients were included in the study. Majority $(44.0 \%)$ patients were in the age group of 21-30 years followed by the age group of 11 to 20 years $(38.0 \%)$. The mean age was found $19.1 \pm 7.6$ years with range from 8 to 30 years (Table 1).

Table 1: Age distribution in the study patients $(\mathrm{n}=50)$

\begin{tabular}{lcc}
\hline Age Group & Frequency & Percentage \\
\hline Less Than 10 Years & 9 & 18.0 \\
11 to 20 Years & 19 & 38.0 \\
21 to 30 Years & 22 & 44.0 \\
\hline Total & $\mathbf{5 0}$ & $\mathbf{1 0 0 . 0}$ \\
\hline
\end{tabular}

*Mean $\pm \mathrm{SD}=18.9 \pm 7.2$; Range $(\min -\max )=8$ to 30 years

Among 50 patients $29(58.0 \%)$ were male and $21(42.0 \%)$ patients were female. Male to female ratio were found 1.4:1 (Figure I).

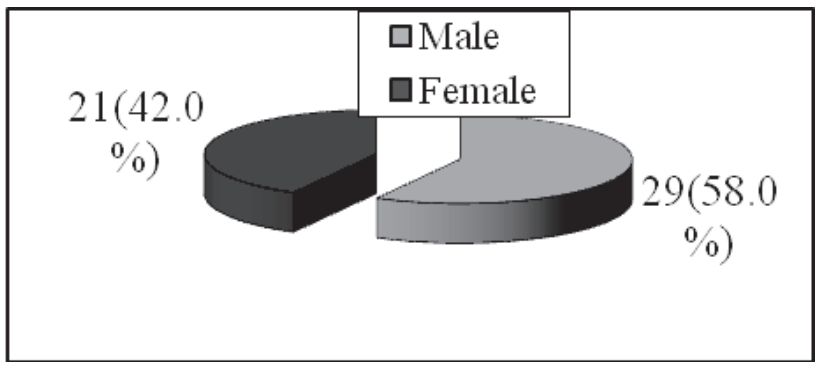

Figure 1: Pie chart showing sex distribution of the study patients $(\mathrm{n}=50)$

It was observed that $39(78.0 \%)$ patients had family history of asthma (Figure II)

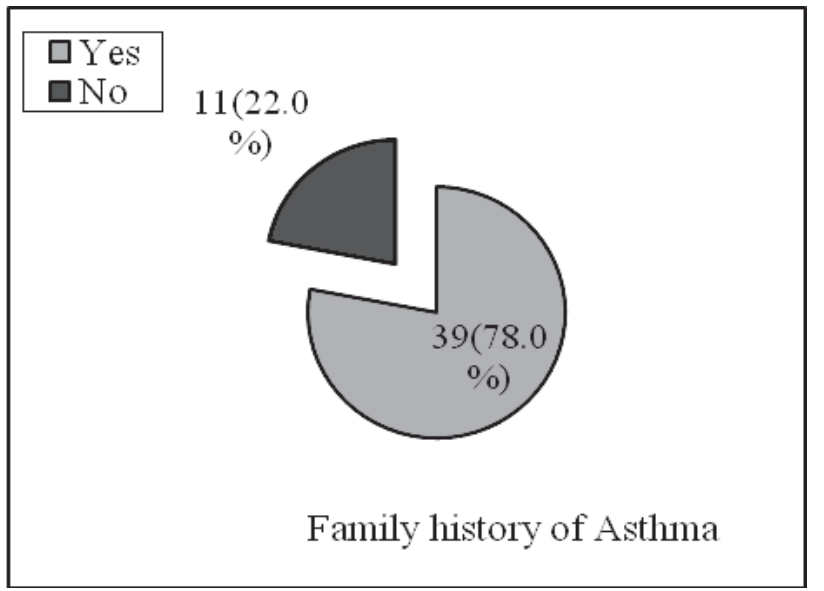

Figure 2: Pie chart showing family history of asthma of the study patients $(\mathrm{n}=50)$ 
Table 2 showed that 29(58.0\%) patients had associated allergic rhinitis and the rest $21(42.0 \%)$ had without any history of allergic rhinitis.

Table 2: Associated Allergic Rhinitis in the Study Patients $(\mathrm{n}=50)$

\begin{tabular}{lcc}
\hline Allergic Rhinitis & Frequency & Percentage \\
\hline Present & 29 & 58.0 \\
Absent & 21 & 42.0 \\
\hline Total & $\mathbf{5 0}$ & $\mathbf{1 0 0 . 0}$ \\
\hline
\end{tabular}

Table 3 showed that $8(16.0 \%)$ patients had associated eczema and the rest $42(84.0 \%)$ patients has no history of associated eczema.

Table 3: Associated Eczema in the Study Patients $(n=50)$

\begin{tabular}{lcc}
\hline Eczema & Frequency & Percentage \\
\hline Yes & 8 & 16.0 \\
No & 42 & 84.0 \\
\hline Total & $\mathbf{5 0}$ & $\mathbf{1 0 0 . 0}$ \\
\hline
\end{tabular}

Table 4 showed that only $2(4.0 \%)$ patients had associate allergic conjunctivitis and the rest $48(96.0 \%)$ patients had absence of associated conjunctivitis.

Table 4: Associated Allergic Conjunctivitis in the Study Patients $(\mathrm{n}=50)$

\begin{tabular}{lcc}
\hline Conjunctivitis & Frequency & Percentage \\
\hline Present & 2 & 4.0 \\
Absent & 48 & 96.0 \\
\hline Total & $\mathbf{5 0}$ & $\mathbf{1 0 0 . 0}$ \\
\hline
\end{tabular}

Trigger factors included cold, dust, exercise, smoke, strong smells, allergen exposure. Table 5 showed that all $(100.0 \%)$ patients had the presence of trigger factors.

Table 5: Associated Trigger Factor in the Study Patients $(\mathrm{n}=50)$

\begin{tabular}{lcc}
\hline Trigger Factor & Frequency & Percentage \\
\hline Present & 50 & 100.0 \\
Absent & 0 & 0.0 \\
\hline Total & $\mathbf{5 0}$ & $\mathbf{1 0 0 . 0}$ \\
\hline
\end{tabular}

\section{Discussion}

Cough variant asthma (CVA) has been recognized as a precursor of asthma or a pre-asthmatic state because of the mildly heightened bronchial responsiveness and efficacy of bronchodilator therapy8. Nevertheless, the accumulating evidence indicates that the pathophysiology is different between CVA and bronchial asthma.

The most fundamental physiologic feature is a heightened cough response to methacholine-induced broncho-constriction in CVA, while this response is rather reduced in bronchial asthma'. The sensitivity of cough receptors located in the superficial layer of the airway wall is normal in CVA as well as bronchial asthma, but heightened in atopic cough.

In this study a total of 50 patientshave enrolled in this study.In this study it has been observed that $42.0 \%$ patients belong to age 21-30 years and the mean age is found 19.1 \pm 7.6 years with range from 8 to 30 years. Yooet allohave showed the mean $( \pm \mathrm{SD})$ age was found $11.4 \pm 2.2$ years, which is lesser with the current study. On the other hand Al-Moamaryet $\mathrm{a}^{11}$ have found that the mean age is $32.05 \pm 10.87$ years. The higher mean age and age range has obtained by the above authors whichmaybe due to geographical variation as well as racial influences.In this study it has been observed that cough-variant-asthma is predominant in male subject where $58.0 \%$ patients are male and $42.0 \%$ populations are female. Male to female ratio is found 1.4.:1. Similarly, Harish and Suryanarayana ${ }^{12}$ have showed $71.7 \%$ male and $28.3 \%$ female. Al-Moamaryet $\mathrm{al}^{11}$ and Yooet $\mathrm{al}^{10}$ have also observed male predominant in their studies, where they have found that $53.8 \%$ and $53.7 \%$ are male respectively.In this series it has been observed that majority (78.0\%) patients have positive family history of asthma. Similarly, Bandyopadhyayet $\mathrm{al}^{13}$ and Khakzadet $\mathrm{al}^{8}$ have showed that family history of Asthma are 47.5\% and $43.0 \%$ respectivelywhich are comparable with the current study. In this present study it has been observed that $58.0 \%$ populations are associated with allergic rhinitis. Similarly, Alvarez et al9havefound airway eosinophilic infiltration in rhinitic patients. In this current study it has been observed that $16.0 \%$ and $4.0 \%$ patients have associated with eczema and conjunctivitis respectively.In this study all patientshave trigger factor. Matsumoto et $\mathrm{al}^{14}$ have developed a closed questionnaire listing of 18 triggers reported by $\geq 1 \%$ of 213 patients in a retrospective survey.In another study6among 32 children with CVA, 25 reported exercise-induced cough and 14 reported cold air-induced cough, and a majority of these patients experienced worsening of cough during specific seasons.

The pathologic feature of CVA is eosinophilic inflammation of the central to peripheral airway, reflected by eosinophilia in induced sputum, biopsied bronchial mucosa, and bronchoalveolar lavage fluid ${ }^{8}$. The diagnosis of CVA has been commonly made based on therapeutic diagnostic procedures, while pathophysiologic diagnosis is ideal. The reason is that measurements of the sensitivity of cough receptors to inhaled capsaicin and cough response to induced broncho-constriction are not possible at most chest 
clinics in the world. The efficacy of a beta2-agonist for a patient's coughing is evaluated to make a diagnosis of $\mathrm{CVA}^{5}$. When the bronchodilator therapy is judged as efficacious, a tentative diagnosis of CVA is made. Then, induction therapy is initiated for resolution of the cough. The induction therapy consists of beta2-agonists, leukotriene receptor antagonists, and inhaled corticosteroids. In some patients whose cough does not subside with the therapy, short-burst oral corticosteroids ( 1 to 3 weeks) may be added. If the cough still does not subside with the therapy, the patient should be referred to cough specialists ${ }^{11}$. When the cough subsides with the induction therapy, long-term management is recommended using inhaled corticosteroids, because $30 \%$ of patients develop typical bronchial asthma within several years.

\section{Conclusion}

In conclusion young male is more commonly affected by cough variant asthma. It has been also found that majority have the family history of asthma. Further large scale study should be conducted to get the real picture of whole country.

\section{References}

1. Takemura M, Niimi A, Matsumoto H, Ueda T, Matsuoka H, Yamaguchi M, Jinnai M, Chin K, Mishima M. Clinical, physiological and anti-inflammatory effect of montelukast in patients with cough variant asthma. Respiration 2012;83(4):308-15

2. Niimi A, Amitani R, Suzuki K, Tanaka E, Murayama T, Kuze F. Eosinophilic inflammation in cough variant asthma. European Respiratory Journal. 1998;11(5):1064-9

3. Johnson D, Osborn LM. Cough variant asthma: a review of the clinical literature. Journal of Asthma 1991;28(2):85-90

4. Kawai S, Baba K, Matsubara A, Shiono H, Okada T, Yamaguchi

E. The efficacy of montelukast and airway mast cell profiles in patients with cough variant asthma Journal of Asthma. 2008;45(3):243-50

5. Dicpinigaitis PV, Dobkin JB, Reichel J. Antitussive effect of the leukotriene receptor antagonist zafirlukast in subjects with cough-variant asthma. Journal of Asthma 2002;39(4):291-7

6. Todokoro M, Mochizuki H, Tokuyama K, Morikawa A. Childhood cough variant asthma and its relationship to classic asthma. Annals of Allergy Asthma Immunology 2003;90(6):652-9

7. Shirahata K, Fujimoto K, Arioka H, Shouda R, Kudo K, IKEDA SI. Prevalence and clinical features of cough variant asthma in a general internal medicine outpatient clinic in Japan. Respirology 2005;10(3):354-8

8. Khakzad MR, Mirsadraee M, Sankian M, Varasteh A, Meshkat M. Is serum or sputum eosinophil cationic protein level adequate for diagnosis of mild asthma?. Iranian Journal of Allergy, Asthma and Immunology. 2009;8(3):155-60

9. Alvarez MJ, Olaguibel JM, Garcia BE, Rodriguez A, Tabar AI, Urbiola E. Airway inflammation in asthma and perennial allergic rhinitis. Relationship with nonspecific bronchial responsiveness and maximal airway narrowing. Allergy. 2000;55(4):355-62.

10. Yoo Y, Koh YY, Kang H, Yu J, Nah KM, Kim CK. Sputum eosinophil counts and eosinophil cationic protein levels in cough-variant asthma and in classic asthma, and their relationships to airway hypersensitivity or maximal airway response to methacholine. Allergy. 2004;59(10):1055-62

11. Al-Moamary MS, Alhaider SA, Al-Hajjaj MS, Al-Ghobain MO, Idrees MM, Zeitouni MO, Al-Harbi AS, Al Dabbagh MM, Al-Matar H, Alorainy HS. The Saudi initiative for asthma-2012 update: Guidelines for the diagnosis and management of asthma in adults and children. Annals of thoracic medicine. 2012 Oct 1;7(4):175.

12. Harish M,Suryanarayana V. A Prospective Study of Sputum Eosinophils in Acute Exacerbation of Asthma. World Journal of Medical Sciences, 2014;10(2):145-149

13. Bandyopadhyay A, Roy PP, Saha K, Chakraborty S, Jash D, Saha D. Usefulness of induced sputum eosinophil count to assess severity and treatment outcome in asthma patients. Lung India 2013;30(2):117

14. Matsuoka H, Uzu T, Koyama M, Koma Y, Fukumitsu K, Kasai Y, Masuya D, Yoshimatsu H, Suzuki Y. Allergic bronchopulmonaryaspergillosis presenting with cough variant asthma with spontaneous remission. Respiratory Medicine CME. 2011;4(4):175-7. 